Mitja Skubic

Universidad de Ljubljana

\title{
OTRO DÍA HABÍA DE VOLVER AL DURO EJERCICIO DE LAS ARMAS
}

1. En El Quijote de Cervantes el pronombre indefinido otro aparece frecuentemente y con varios valores semánticos. Aquí nos interesan sólo los valores temporales en el sintagma otro día y aun queremos limitarnos a una sola acepción de dicho sintagma que es 'al día siguiente', es decir cuando el sintagma sirve para introducir una acción o situación de posterioridad, un futuro en el pasado, como en El se lo contó todo [...] que fue poner más deseo en el licenciado de hacer lo que otro día hizo, I,5. Tales pasajes, con otro más un substantivo de tiempo, en la novela no son excesivos, ya que dicho sintagma puede aparecer con tal sentido sólo en la narración, en una secuencia de acontecimientos, a condición de referirse a un hecho acaecido al día, mes, año siguiente a otro en el pasado; según las mayores gramáticas españolas, para el español actual, también en el futuro. En la novela cervantina esta restricción sobre el empleo en la esfera del futuro no es vigente cuando el sintagma sirve para expresar un día, semana, mes, año cualquiera, es decir en cuanto al tiempo no exactamente determinado, y sobre todo no inmediatamente siguiente, como en II,66: pero Sancho le respondió que era descortesía dejar que su amo le esperase, que otro día, si se encontrasen, habría lugar para ello. El valor semántico, un hecho en un futuro no determinado, es análogo al sintagma otra vez que encontramos en la carta que Sancho hizo escribir a su mujer Teresa: Esto no lo entenderás tú, Teresa mía, por ahora; otra vez lo sabrás, II,35. Con la locución adverbial de tiempo en un futuro no determinado otro día hay casos análogos, dos en todo, en el Diálogo de la lengua de Juan de Valdés, citados según la edición de Espasa-Calpe, Madrid 1976: Abasta que entendáis el propósito para que los digo; la sentencia, otro día la entenderéis, pág. 46; Yo no entiendo bien [...] - No importa, otro día lo entenderéis, pág. 128.

Si los pasajes del sintagma otro día con el valor 'al día siguiente, el día después' no son muchos, todavía son bastantes para suscitar interés. Subrayamos que con el artículo determinativo el sintagma es un adverbio de tiempo que atañe la esfera preterital, que sin embargo sirve para expresar un hecho temporalmente indeterminado, como en Escribióme el Duque, mi señor, el otro día, II,51 - conforme, añadimos, al francés il m'a écrit l'autre jour -, mientras, al contrario, sin artículo sirve al verbo para expresar una noción temporal bien determinada; la determinación es relativa respecto a una acción o situación en el pasado: una verdadera paradoja sintáctica. Para comprobar el valor semántico del sintagma sin artículo en El Quijote será suficiente llamar la atención sobre los pasajes de sólo algunos capítulos de la segunda parte de la novela cervantina:

Sucedió, pues, que otro día, al poner del sol y al salir de una selva, tendió don Quijote la vista por un verde prato, $\mathrm{I1}, 30$;

Pero don Quijote no se le quiso poner [el vestido], diciendo que otro día había de volver al duro ejercicio de las armas, II,34; 
Y así, habiendo dado la traza y órdenes que sus criados y vasallos habian de guardar con Sancho en el gobierno de la ínsula prometida, otro día, que fue el que sucedió al vuelo de Clavileño, dijo el Duque a Sancho que se adeliñase y compusiese para ir a ser gobernador, II,42;

pero consolóse con ver que Sancho le había dejado unas botas de camino, que pensó ponerse otro día, II,44;

Otro día le pareció a don Antonio ser bien hacer la experiencia de la cabeza encantada, II,62;

Aquella noche la pasaron amo y mozo en mitad del campo, al cielo raso y descubierto, y otro día, siguiendo su camino, vieron que hacia ellos venía un hombre de a pie, II,66.

2. Los grandes diccionarios del español registran el uso de este sintagma, en el español actual, también para la esfera del futuro, no tanto para la posterioridad, para una acción posterior respecto a una situación en el pasado. Así el de la R.A.E., 20a ed., Madrid 1984. s.v. otro: - 6. Con $a$ y artículo, ante los substantivos como día, semana, mes, año equivale a "siguiente": Convinimos en reunirnos de nuevo al otro día; $A$ la otra semana nos pagarán. De la misma manera CLAVE, Diccionario de uso del español actual, $4^{\mathrm{a}}$ ed., Madrid 2000, s.v. otro: - Precedido de artículo determinado y seguido de substantivos como 'día', 'mañana', 'tarde' y 'noche' los sitúa en un pasado cercano: El otro día me encontré con tu primo. En expresiones como al otro día o al otro mes, equivale a siguiente. En el de María Moliner, Diccionario de uso del español. $2^{a}$ ed., Madrid 1999, se lee para el mismo sintagma: - 3. Precedido de "el" o "la" y antepuesto a palabras como "día, noche, semana" etc. sirve para aludir a un pasado cercano: La otra noche nos encontramos con tus padres en el cine. - 4. Precedido de "al" o "a la" y antepuesto a día, semana, etc. equivale a "siguiente": Me fui a verle y al otro día todo estaba resuelto. El Diccionario de María Moliner indica, s.v. día, también el sintagma sin artículo y comenta: - Expresión con que se difiere una cosa para un día indeterminado: Otro día te lo daré. En la Gramática de Manuel Seco et alii, Aguilar, Madrid 1999, encontramos S.v. otro: - 4. Inmediato en el tiempo o en el espacio. Precedido del art. El Cuevas, Finca 238: Al otro día, Manca pidió a Jeromo que sacara el viejo coche. Es curioso constatar que la Gramática descriptiva de la lengua española, dirigida por Ignacio Bosque v Violeta Demonte, publicada por la R.A.E, Madrid 1999, no lo menciona. No se encuentra una mención tampoco en las célebres obras sobre la sintaxis española de Samuel Gili Gaya y de Rodolfo Lenz: creemos que tanto el Curso Superior de Sintaxis Española como la Oración y sus partes están consagradas a los problemas sintácticos, mientras el sintagma tratado atañe sí la sintaxis, pero constituye también una cuestión semántica.

3. Al valorar un fenómeno linguiístico romance es un deber examinar la situación en el latín. Merece la pena recordar que las realizaciones en el romance como altro, autre, otro se originan en el pronombre indefinido latino ALTER 'el segundo de los dos'. Pero, los latinistas constatan su confusión semántica con el pronombre indefinido ALIUS 'otro 
cualquiera, no el primero'; además, ALTER ya en el latín asumió también el valor de 'el siguiente'. El traspaso semántico está psíquicamente motivado. Es de observar que el valor temporal de posterioridad aparece también en el sintagma latino SEQUENTI DIE.

4. Buscando los modos de expresar la misma noción temporal en otras lenguas románicas, no podemos pasar por alto el de la italiana. Y en verdad, si hoy en día en italiano el sintagma tratado no aparece, hay casos análogos a los encontrados en El Quijote, pero muy pocos. En el Decamerón - y sabemos la influencia que Bocacio efectuó en toda la vieja narrativa española - el sintagma ( $l$ ') altro dì /giorno/anno aparece con el valor semántico de 'al día siguiente', etc., como en Appresso questo, commise il re [...] che [...] l'altra mattina appresso gli comandasse che egli indietro al re tornasse, IX, 1 ; y también con el valor del 'día después de mañana', como en domane o l'altro dì , III,1; estimo che onesta cosa sia che domane e l'altro di, come i passati giorni facemmo, dal nostro dilettevole novellare ci asteniamo, VII, C (esfera temporal es el presente). Por lo demás, el renacentista italiano recurre al participio presente del verbo seguire: il dì seguente nella Piazza il mena, IV,2; Avenne che il dì seguente, II,7.

Conviene añadir que los viejos textos italianos, y tampoco Bocacio en el Decamerón, para la noción de 'al día siguiente' no conocen para nada el adverbio l'indomani, hoy en italiano ampliamente utilizado.

5. De los textos literarios españoles, anteriores a la época cervantina, es quizás útil recordar que en Celestina un empleo de otro día no se encuentra sino muy pocas veces. No hay de qué maravillarse: dicho sintagma pide una narración y ésta es rara en Celestina, toda consagrada - con sólo algunas excepciones - a reflexionar sobre situaciones actuales. Aparece el sintagma con el artículo para expresar una noción temporal no determinada en el pasado: Este es el que el otro día me vido, auto IV, y, excepcionalmente, para expresar una noción temporal determinada, es decir, posterior, relativa a una situación o acción en el pasado: soñó que se veya embuelto en el manto de su amiga, y otro día mataronle, (Calisto); quando los otros reposan en sus camas, preparas tú el trabajo para sofrir otro día, (Celestina), auto VI; Si la hoviere, ogaño, si no, otro año; si no, nunca, (Sempronio), auto III, en la esfera del futuro, 'el año siguiente'.

6. De particular importancia nos parece el empleo del sintagma otro día en el sentido de 'al día siguiente' en Lazarillo de Tormes. Aparece sólo en la narración, así en el relato de la convivencia de Lazarillo con el viejo ciego o en su vida con el clérigo tacaño, es decir en la presentación de los acontecimientos durante su aprendizaje; en las partes narrativas los ejemplos no son raros: halló la fuente y cayó en la burla $[. .$.$] Y luego otro$ día [...] sentéme como solía, Tractado primero; Otro día, no pareciéndome estar alli seguro, fuime a un lugar que llaman Maqueda; Vino el mísero de mi amo, y quiso Dios no miró en la oblada [...] Y otro día, en saliendo de casa, abro mi paraíso panal; Y así estuve con ello aquel día y otro gozoso; Otro día fue por el señor mi amo visto el daño; Luego otro día que fui levantado, Tractado segundo. Para el valor semántico de otro día es 
precioso encontrar en el tractado primero: Donde hallaba buena acogida y ganancia, deteníamonos; donde no, a tercero día hacíamos Sant Juan.

7. Para destacar el uso en el texto original vamos a presentar en seguida de los pasajes de $E l$ Quijote, ya citados en el primer párrafo, las versiones italiana y rumana. La italiana, por ser indudable la influencia de la vieja narrativa italiana sobre la lengua cervantina; la rumana, por la formación excepcional del adverbio en el rumano con el número ordinal. Y además, para el rumano, es más que interesante la aparición del lat. ALTER, en rumano alto en II,34. Serán citadas dos versiones italianas por ser publicadas a más de setenta años de distancia, la primera bajo el título Michele Cervantes di Saavedra, L'ingenioso idalgo don Chisciotte della Mancia con Sancio Pancia suo scudiero, Sonzogno, Milano, 1883, la segunda con Miguel Cervantes, Don Chisciotte della Mancia, Einaudi, Torino 1957. En esta es visible el uso generalizado de l'indomani. La traducción rumana es del año 1987, BPT, Minerva, Bucureşti.

Avvenne, dunque, che il giorno seguente, al tramontare del sole, uscendo da una selva, distese don Chisciotte gli occhi per un verde prato;

Accadde dunque che l'indomani, al tramontar del sole, all'uscita da una selva don Chisciotte spinse lo sguardo per un verde prato;

Se intimplă, dară, că a doua zi, către asfințitul soarelui, pe cînd ieşeau dintr-o dumbravă, îşi aruncă ochii don Quijote pe o pajişte verde;

ma don Chisciotte rifiutò il suo col dire che dovendo riprendere quando che fosse;

dicendo che l'indomani egli doveva tornare al duro esercizio delle armi;

Don Quijote nu vru s-o primească, sub cuvînt că de la o zi la alta avea să se întoarcă iarăşi la aspra îndeletnicire a armelor;

Un altro dì, che fu il susseguente al volo di Clavilegno, disse il duca a Sancio;

All'indomani del giorno in cui aveva avuto luogo il volo di Clavilegno, il Duca disse a Sancio;

a doua zi, care fu aceea de urmă după zborul lui Lemnopiron;

ma si racconsolò poi vedendo che Sancio gli aveva lasciati certi stivali da viaggio che egli divisò di calzare nel dì seguente;

si confortò vedendo che Sancio gli aveva lasciato delle scarpe di viaggio e pensò di mettersi quelle il giorno dopo;

dar se mai linişti puşin văzînd că Sancho îi lăsase o pereche de cizme de drum, pe care se gîndi să le pună a doua zi;

Parve opportuno a don Antonio nel dì seguente di fare la sperienza sopra la testa incantata; 
All'indomani don Antonio credette opportuno far l'esperienza della testa incantata

A doua zi găsi cu cale Don Antonio că n-ar fi rău să facă încercarea cu capul fermecat;

Là passarono quella notte, padrone e servitore, in mezzo alla campagna, a cielo scoperto, e continuando nel dì seguente il viaggio, videro venire alla volta loro un uomo a piedi;

Quella notte padrone e servo la trascorsero in mezzo alla campagna a cielo raso e scoperto, e l'indomani, proseguendo il loro viaggio, videro venire verso di loro un uomo a piedi;

Acea noapte şi-o petrecură stăpîn şi slugă in inima cîmpului, sub tăria cerului, iar a doua zi, urmîndu-şi drumul mai departe, văzură că venea spre ei un om pe jos.

Constatamos una cierta concordancia en el uso del sintagma otro día de la versión rumana con el original español: la concordancia no es total, ya que el rumano exige el empleo del artículo determinativo y, sobretodo, emplea el adjetivo numeral ordinal a doua y no el continuador del latino ALTER con la excepción que notamos. Claro está, no es posible ni de lejos pensar en una misma situación, es decir, en la continuación y conservación de un fenómeno común originado en el latín, como se constata en los conocidos elementos lexicales del tipo FORMOSUS formoso/hermoso, frumos o también sintácticos como en el empleo de más/mais, mai para la comparación del adjetivo y adverbio. El sintagma en el español de Cervantes y en los otros textos españoles, viejos sobre todo, se origina, creemos, en la herencia de formar este adverbio de tiempo en el latín; para el rumano preferimos ver un calco sintáctico según las lenguas eslavas, mientras que el empleo de otro día será una particularidad sintáctico-semántica del español, heredada del latín.

\section{OTRO DÍA - 'DRUGI DAN' PRI CERVANTESU}

Drugi dan v pomenu 'naslednji dan, naslednjega dne', kar najdemo večkrat na pripovedovalnih straneh Cervantesovega Don Kihota kot otro día (brez določnega člena) iz lat. ALTERO DIE, se $v$ romanskih jezikih izraža $\mathrm{z}$ različnimi ustreznicami: iz lat. prislova časa (DE)MANE le lendemain, l'indomani, tal indoman ali iz deležnika sedanjega časa glagola SEQUI, pog. * sequere, al día siguiente, no dia seguinte; samo romunščina se je zatekla k vrstilnemu števniku, kar imamo za kalk po slovanskem vzorcu. Sintagma pri Cervantesu in v starejših španskih besedilih je seveda ohranjanje rabe v latinščini. 